\title{
The Challenge of Conflict of Interest in Medicine
}

\section{Citation}

Thompson, Dennis F. 2009. The challenge of conflict of interest in medicine. Zeitschrift für Evidenz, Fortbildung und Qualität im Gesundheitwesen 10(3):136-140.

\section{Published Version}

doi:10.1016/j.zefq.2009.02.021

\section{Permanent link}

http://nrs.harvard.edu/urn-3:HUL.InstRepos:10384893

\section{Terms of Use}

This article was downloaded from Harvard University's DASH repository, and is made available under the terms and conditions applicable to Open Access Policy Articles, as set forth at http:// nrs.harvard.edu/urn-3:HUL.InstRepos:dash.current.terms-of-use\#OAP

\section{Share Your Story}

The Harvard community has made this article openly available.

Please share how this access benefits you. Submit a story.

\section{Accessibility}




\title{
The Challenge of Conflict of Interest in Medicine
}

\author{
Dennis F. Thompson* \\ HARVARD UNIVERSITY \\ Z. Evid. Fortbild. Qual. Gesundh. wesen (ZEFQ) 103 (2009) 136-140
}

The expanding relationships between industry and medicine have produced great benefits. [1] [2] Industry support for medical research has led to important therapeutic breakthroughs. Such support has helped medical education at all levels. Academic research, in turn, has provided industry with many basic ideas that lead to the development of new drugs and medical devices. However, as these relationships have grown, the conflict between the financial goals of industry and the professional goals of medicine is creating significant risks for not only the profession but also the public. [3] [4] [5] What should be the primary goals of medicine- - high quality research, responsible patient care and excellent medical education-may be compromised by the undue pursuit of financial gain. That tension is what policies for regulating conflicts of interests should be designed to control.

\section{The Concept of Conflict of Interest}

A conflict of interest is a set of circumstances that are reasonably believed to create a substantial risk that professional judgment of a primary interest will be unduly influenced by a secondary interest. [6] [7] The primary interest refers to the purpose of the professional activity, such as the welfare of patients or the quality of research. The secondary interest is typically financial gain. The belief about the risk of the effects of the conflict is based on past experience in other relevant cases.

To avoid common misunderstandings of the concept that can lead to misplaced and ultimately ineffective policies, it is important to appreciate the sig- nificance of each of these three main elements of a conflict of interest.

The primary interest that conflict of interest policies seek to protect varies according to the purpose of the activity. The interests include maintaining the integrity of research, the welfare of patients, and the quality of the training of medical students and the continuing education of physicians. These should be the primary interest both for individuals in a professional role and for any medical institution. Describing exactly what the primary interest is for professionals and for various institutions may be controversial. Sometimes primary interests may conflict with each other (the welfare of the patients in a research protocol and the successful completion of the research, for example). But whatever the primary interests are, the point of regulating conflicts of interest is to try to ensure that the primary interests have decisive weight in the professional decisions an individual or institution make. Conflicts of interest are thus quite different from the conflicts between primary interests, which are more like the familiar dilemmas of medical ethics, in which neither value can be said in advance to have priority.

Secondary interests include the desire for professional advancement, recognition for personal achievement, favors to friends and family, assistance to one's students and colleagues, and most saliently financial gain. Conflict of interest rules typically focus on financial gain, not because it is more corrupting than the other interests but because it is relatively more objective, fungible, and quantifiable. It is therefore more effectively and fairly regulated than other secondary interests. Most secondary interests including financial gain are perfectly 
legitimate (even desirable) goals within limits. The secondary interests are objectionable only when they have greater weight than the primary interest in professional decisions.

The conflict is not an occurrence but a set of circumstances that create or increase a risk that primary interests will be compromised as a result of the pursuit of secondary interests. The claim that there is a conflict of interest expresses a tendency. It is based on common past experience: we have learned that under certain circumstances professional judgment about a primary interest is at risk of being unduly influenced by a secondary interest. Rules that control this danger, even if the threat is actualized in relatively few cases, are intended to protect against this risk. Therefore, a conflict of interest exists whether or not a particular individual or institution is actually unduly influenced by the secondary interest. In any particular case, individuals may be said to have a conflict of interest even though their decisions do not actually impede primary professional goals or violate primary professional obligations.

\section{The Purposes of Conflict of Interest Policies}

Institutions, professional organizations, and governments on behalf of the public establish policies to address the problem of conflict of interest. The policies try to ensure that professional decisions are made on the basis of primary, not secondary interests. To the extent that they are effective in this general goal, they serve two more specific purposes.

First, the policies help maintain the integrity of professional judgment. [8] [9] Bias is the most salient way in which integrity can be compromised [10] [11]. Violations of other standards of professional practice such as timely publication of research, fair treatment of students and post-docs, and openness with patients are also risks. The policies do not assume that any particular professional will necessarily let financial gain influence his or her judgment. The policies seek to minimize the risk of undue influence by secondary interests, most prominently personal financial gain, that should be irrelevant to the merits of decisions about the conduct of research, teaching, and patient care.

Second, the policies help sustain public confidence in professional judgment. [12] Here the point is to minimize or eliminate circumstances that would cause reasonable persons to suspect that professional judgment has been improperly influenced, whether or not it has. The public includes not only patient and research subjects, who may have other concerns on their mind, but legislators, foundation heads, editorial writers and other opinion leaders. To the extent that the public and public officials distrust the profession, they are likely to demand greater external regulation, and to supply fewer resources for its primary activities. When an individual professional acts in ways that lead to distrust, the consequences may affect colleagues, patients, and the institution as a whole. Similarly, institutional practices can be the source of distrust, with effects that may be even more damaging than those of individuals. Once trust is lost, it is difficult to restore.

\section{Misplaced Objections to Conflict of Interest Regulation}

Many objections have been raised against the increasing regulation of conflict of interest. [13] [14] [15] But it is the application to individuals seems to provoke the most resistance. Individuals accused of having a conflict of interest often say that they would never let financial interests influence their decisions. This objection to regulation misses the point. Because the conflict is a set of circumstances that refer to a generic risk rather than the individual decision in a particular case, the existence of a conflict of interest does not imply that any individual is improperly motivated. Still, an individual might still object that it is not fair to generalize in this way: look at my actual decisions and my eminent reputation. However, conflict of interest rules are by their nature 
designed to avoid the need to investigate individual cases in this way. For at least two reasons they are not directed to the motives in a particular case.

First, it is improperly intrusive to conduct the kind of investigation that would be necessary to determine how much influence each of the various interests had in a professional decision in any particular case. Fair hearings could not be held and reliable conclusions reached without risking violations of rights of privacy of the many individuals who may be involved, and without distracting many people from their other more important work.

Second, it is usually impossible for the potentially affected parties to determine with any degree of confidence that a particular decision was improperly motivated. Generally, there are multiple considerations that affect judgment in medical decisions. Citizens, students, physicians, researchers, and others who are affected by the decision but do not know the decision maker are not in a position to assess motives in particular cases. Even if they did know the decision maker, they would find it virtually impossible to determine whether secondary interests motivated a decision. The decision makers themselves are not always fully aware of their motivations.

Another, closely related, objection is sometimes raised against a claim that an individual has a conflict of interest. This objection agrees that we should ignore motives but denies that the conditions under which decisions are made is relevant to assessing the professional's conduct. Judge my decisionthe results of the research, the content of the lecture, the prescription of the drug-not my financial interests. Again the problem is that many people affected by professional decisions are not in a position to judge their validity. Those who are competent to judge may not be able to do so until after the damage has been done. Furthermore, the objection completely ignores one of the main purposes of conflict of interest policies-maintenance of public trust. Even valid decisions and honest research may not be widely accepted as such if they are made or conducted under conditions in which secondary interests are prominent.

\section{The Misuse of "Appearance" in Conflict of Interest} Conflict of interest policies should not state that professionals should avoid "even the appearance of a conflict of interest." All conflicts of interest involve perceptions or appearances because they are specified from the perspective of people who do not have sufficient information to assess the actual motives of a decision maker and the effects of these motives on the decisions themselves. Contrasting actual with perceived conflicts leads to two problems.

First, the contrast encourages the mistaken idea that the appearance is not as bad as the actual conflict. It undermines the rationale for prohibiting any conflict of interest because it suggests that there is no conflict unless the decision maker was actually motivated to favor secondary over primary interests. When a professional's judgment is actually distorted by acceptance of a gift or the prospect of stock options, the violation is no longer simply a conflict of interest but emphatically the victory of the wrong interest. It becomes another, different kind of offense, one that may involve negligence, abuse of power, scientific misconduct or even dishonesty and bribery.

Second, separating appearances from real conflicts leads to overly broad and excessively subjective rules, which can be used to raise questions about conduct that is perfectly proper. With a loose notion of perception or appearance, circumstances that are suspicious only to uninformed people or muckraking reporters can be the basis of indiscriminate charges of conflicts of interest. Charges of conflicts of interest should be limited to circumstances specified by rules that are objectively grounded in past experience and interpreted by reasonable persons on the basis of relevant and publicly available facts. 


\section{Standards for Assessing Conflicts of Interest}

Conflicts are not binary. They can be more or less severe. The severity of a conflict depends on (1) the likelihood that professional decisions in the relevant circumstances tend to be unduly influenced by a secondary interest; and (2) the seriousness of the harm or wrong that could result from such influence. Both of these assessment are based not mainly on the particular case in question, but on other cases in similar circumstances.

\section{Severity of conflict of interests}

\begin{tabular}{|c|c|}
\hline $\begin{array}{c}\text { Likelihood of Undue } \\
\text { Influence }\end{array}$ & $\begin{array}{c}\text { Seriousness of Harm or } \\
\text { Wrong }\end{array}$ \\
\hline $\begin{array}{c}\text { Value of } \\
\text { Secondary Interest }\end{array}$ & $\begin{array}{c}\text { Value of } \\
\text { Primary Interest }\end{array}$ \\
\hline Scope of Conflict & Scope of Consequences \\
\hline & \\
Extent of Discretion & Extent of Accountability \\
\hline
\end{tabular}

In assessing the likelihood, we may assume that within a standard range the greater the value of the secondary interest (e.g. the size of the financial gain), the more probable its influence. Although absolute value is important, the secondary interest should generally be measured relative to typical income for the relevant class of professionals, and relative to the scale of the practice, projects and institutional budgets.

Scope of conflict refers to the duration and depth of the relationship that generates the conflict. Longer and closer associations increase the scope. A continuing relationship as a member of the board or limited partner, for example, creates a more serious problem than the acceptance of a one-time grant or gift. Consulting agreements that extend for years or honoraria that cover years of speaking are more problematic. Likewise, serving on a company's scientific advisors board that more intimately ties the professional to the fate of the company is more likely to affect judgment than occasionally speaking for the company.

The extent of discretion - how much latitude a professional enjoys in the making of major decisions-partly determines the range of the probabilities. The more closely the research methods follow conventional practice, the less room there is for judgment, and hence for improper influence. Also, the less independent authority the professional has in a particular case, the less latitude there is for improper influence. A conflict involving a lab technician, for example, is generally less severe than one involving a principal investigator. A professional may also enjoy less independent authority if there is a large team overseeing the research trial and a mechanism for external auditing.

In assessing the seriousness of a conflict, we should consider first the value of the primary interest. This value consists of both benefits and costs. Some relationships that present a conflict of interest also advance the primary aims of science and medicine and thus the primary aims of medical and scientific professionals. In some situations, it may be necessary to accept a conflict of interest in order to advance a primary interest. For example, allowing a scientist who is the primary discoverer and patent holder of a promising new intervention to participate in designing a clinical trial may be the only way to ensure that the results are scientifically valid.

At the same time, these commercial relationships can undermine the very primary values that they are intended to promote. They can have damaging effects on the integrity of the research, teaching, or clinical practice. In weighing these costs, we should consider the possibility of harm to the subjects, students and patients, damage to the objectivity of the research and 
education, and the loss of confidence in the judgment of the individual professional and collaborators.

The greater the scope of consequences, the more serious the conflict. Beyond its impact on the research of a particular individual, a conflict may have effects on the research and teaching of colleagues. A drug company's sponsorship of a research project could raise about the work of other researchers in the institution, and weaken their ability to raise funds for other sources. A professor's close connections with industry could not only raise doubts about the objectivity of his classes (for example, discounting his criticisms of industry because of suspicions that he is overcompensating for his relationships). It could also have negative effects on the careers of his teaching assistants, and the collegial culture of the institution.

Finally, a conflict is more serious the less extensive the accountability of the educator, physician or researcher. If the decision of a physician is reviewable by colleagues or authorities (who do not themselves have conflicts of interest), then there is less cause for concern. But the reviewers must be genuinely independent and effective.

Even if professionals are accountable for particular decisions, however, they may escape scrutiny for the cumulative effects and for the broader policy implications of their decisions. The informal norms and policies of a hospital or HMO represent judgments that, no less than explicit decisions in particular cases, may be improperly influenced by secondary interests. Similarly, the peer review process is a better check on the results of particular research projects than it is on the direction and significance of the research enterprise as a whole.

\section{Procedures for Dealing with Conflicts of Interest}

The standards should guide the choice of procedures and the way in which they are deployed. In general, the more severe the conflict, the more rigorous the procedures should be. Three major types of procedure are commonly used to deal with conflicts of interest: disclosure, management and prohibition.

\section{Disclosure}

Disclosure is intended to give people who may be affected by professional decisions the information they need to assess whether those decisions are consistent with the primary interest. The key question is: who should disclose what to whom?

The standard for disclosure should be what the affected persons should want to know to assess the severity of the conflict of interest. Specifically, information should be disclosed that is relevant to evaluating to the value and scope of the interests and the extent of discretion and accountability (see the table above ). Although there is no systematic evidence regarding the relationship between the level of remuneration and the risk of bias, it is reasonable to require disclosure in order to address public confidence.

Disclosure may be necessary but it is usually not sufficient. There is great variation in how disclosure is implemented. [16] The people affected by the decisions may not be able to do anything about the disclosure. Patients, students and the public may have no way of assessing what the disclosure means, and no alternatives if they were to conclude that disclosed conflict is not acceptable. As a result of disclosure, patients and research subjects may become more trusting even when they should be wary. Furthermore, disclosure can undermine public confidence in professional activity if it is not combined with other procedures. This point is especially important in the case of institutional conflicts of interest. The risk of compromising the mission of medical schools and research institutes in the pursuit of financial gain for the institution has grown faster than the procedures for dealing with it. [17] 


\section{Management}

Management techniques are necessary when disclosure is inadequate and prohibition of the activity is not a desirable option because the participation of the conflicted professional is necessary). Management may include divestiture of financial interests, creation of blind trusts, assigning a colleague without a conflict to obtain the informed consent from research participants, limiting participation of the conflicted professional in the project or practice to areas where he or she has unique expertise, and establishing an independent oversight body. However, management turns into simply permitting unless sustained and independent oversight procedures are put in place.

\section{Prohibition}

With this procedure, the professional who has a serious conflict of interest is not permitted to participate in the activity in question. Prohibition must usually operate in conjunction with disclosure. We do not know what to prohibit until the financial interests are disclosed at least to someone in authority. Prohibition may refer to specific individuals but it can also express a general policy. For example, a rule may state that no member of a committee developing practice guidelines may be an employee of a company that manufactures a drug or device covered by the guidelines. Prohibition can be administered in degrees: for example, a researcher who has a patent on the drug being tested in a clinical trial might not be allowed to serve as principal investigator but might be permitted to serve as a consultant about the dosage and administration of the drug; or the director of research at a biotech company might not be permitted to serve as the director of a continuing education course but might be invited to serve on a panel or program on recent developments in a clinical specialty.
Although each of the procedures may be used alone, they are usually, and more effectively, combined in various ways. For example, even when disclosure is not sufficient - as is often the case-it may be still be essential as part of a comprehensive policy. Some level of disclosure is necessary for both management and prohibition of conflicts of interests.

\section{Conclusion}

Medicine today faces many difficult challenges-high costs of treatment, lack of availability of insurance, prevalence of medical error, and decline of financial support for research, among others. In comparison, the problem of conflict of interest may seem less significant. But in an important sense, conflict of interest is the most serious challenge because none of the others can be adequately met if conflicts are not well managed. Dealing successfully with the other problems depends on the capacity of individuals and institutions to make decisions not mainly on the basis of commercial considerations but on the basis of the essential goals of the medical profession. Failure to deal with the challenge of conflict of interest can undermine efforts to address the other serious problems the medical profession faces today. 


\section{Addendum: Institutional Conflicts of Interest}

Institutional conflicts of interest arise when an institution's own financial interests pose a risk to its primary interest in pursuing the mission of providing quality health care, medical education or clinical research. Institutional conflicts typically appear when an the value of equity that an institution holds in a company, or a patent that the institution licenses to a company, can be affected by research conducted within the institution. If the potential for financial return to the institution is significant, there is a risk that the primary goals of the institution may be compromised. With an eye toward enhancing the institution's financial resources, institutional officials may make decisions that they would otherwise avoid-relaxing rules, allowing exceptions, making personnel appointments, or allocating resources in ways that protect the institution's investments more than its mission.

The influence of the financial considerations may cumulative, sometimes not noticeable at first, as the priorities of the institution shift gradually over time in response to financial opportunities. Certain kinds of research or certain kinds of therapies may receive more attention than they would deserve if decisions were made strictly on the scientific and medical merits.

The problem of institutional conflicts has not received as much attention as individual conflicts, but

\footnotetext{
* The distinction between institutional and individual conflicts of interest is not the same as the distinction between institutional and individual corruption. In the discussion of conflicts, the terms (institutional/individual) refer to the agents whose interests are in question, whereas in the discussion of corruption the terms refer to the forms that the influence takes. Thus, individual conflicts can be instances of institutional corruption (as when an individual researcher receives support from a corporation for research in his lab rather than for his personal profit).
}

its consequences can be at least as damaging-in some cases more damaging in the long run-than those of individual conflicts. If not properly addressed, institutional conflicts can undermine the work and reputation of the entire institution, including the members who are themselves strictly avoiding individual conflicts of interest.

Institutional conflicts of interest are in three respects more difficult to deal with than individual conflicts. First, in the case of individual conflicts there are usually opportunities for review at multiple levels of the institution by authorities who are relatively independent and do not themselves stand to gain from the secondary interests. In the case of institutional conflicts, it is more difficult to establish oversight that is truly independent. Everyone potentially stands to gain, often the highest authorities most of all. The reputation and tenure of chief executives and other high officials often depends on their success in improving the financial health of the institution, even if profit is not the aim. Professionals and staff at all levels may be reluctant to question practices that seem to be improving the institution's financial welfare.

Second, the potential gain from a secondary interest is not personal in the same way as it is in individual conflicts. The officers of the institution do not directly profit from the institution's investments (though of course as noted their careers may be affected by their success in this area). Their decisions can be more easily rationalized as serving the institution rather than themselves. And in fact the financial gains often do serve the institution's primary mission. Returns on the investments may be distributed to worthy research, education and practice. But it is precisely because this claim is so plausible (and it often valid) that the serious conflicts are ignored or downplayed. No one is inclined to undertake a careful and continual review to determine whether all the secondary interests are actually serving or undermining the primary interests of the institution. 
Third, for a similar reasons, the public may initially be more tolerant of these conflicts than individual conflicts, which in turn may make the institutional leaders less concerned about them. As the authors of an important comment on institutional conflicts write: "society recognizes that health care institutions need to obtain funds to carry out their missions and sanctions institutional pursuit of such funding. Society may not view this as self-interested behavior and consequently may erroneously be more tolerant of circumstances in which an institution's financial interests may compromise the integrity of its missions than of similar situations involving individual conflict of interest." [18]

Because no decision maker in an institution is fully free of conflict in the case of institutional conflicts, it is not possible to establish a fully independent process for assessing such conflicts. That difficulty has led some to suggest that more rigorous regulation by government is necessary. But such regulation has its own familiar difficulties. It is by no means clear that the government officials are better positioned to understand the primary mission of these institutions, and to strike the delicate balance between encouraging commercial relationships between industry and health care institutions, and protecting the integrity of research, practice and education.

Although there is no perfect solution, the most suitable authority for making judgments about institutional conflicts is the board of trustees, or the equivalent governing body. In their fiduciary role, members of the board are responsible for giving priority to the longer term interests of the institution. Standing at greater distance from the day to day pressures of decision making, they can more judiciously assess the impact of the financial interests on the institution's core mission. They have access to more comprehensive information about the finances of the institution, some of which may be confiden- tial. They are also better positioned to help the chief executive resolve disputes about conflict of interest between schools and other units within the institution. (The school of public health, for example, may think that investments in certain products create a more serious risk to the whole institution than does say the business school.) More generally, the decisions of a Board are more salient within and beyond the institution. When the Board takes up an issue, the concerned public is more likely to take notice.

Boards are more likely to take seriously their responsibility for institutional conflicts if their members have direct responsibility for ensuring that these conflicts do not undermine the long term primary interests of the institution. They should establish their own committee, partially on the model of the audit committee, charged with regularly reviewing the impact of the institution's financial relationships on its core mission. The committee should include members who do not themselves have any conflicts, and at least one person who is completely independent of the board and the institution. The committee should submit a formal report to the board each year, analyzing the institution's financial relationships that may affect the institution's core activities, and the ways in which the institution is managing any conflicts. The report should be made available to the public, to the extent consistent with the requirements of confidentiality. In large institutions, the committee may find it helpful to have the assistance of a working committee, composed of professionals and staff within the institution, which would conduct more frequent reviews and special investigations. Such a committee should report directly to the Board's committee. 


\section{REFERENCES}

* Alfred North Whitehead Professor of Political Philosophy and Director Emeritus of the Edmond J. Safra Center for Ethics at Harvard University. Parts of this article are based on Thompson, DF. Understanding conflict of interest in medicine. $\mathrm{N}$ Engl J Med 1993; 329: 573-76

[1] Blumenthal D. Academic-Industrial Relationships in the Life Sciences $N$ Engl J Med 2003; 349:2452-245.

[2] American Council on Science and Health. Collaboration Between Science and Industry: Pro's and Con's of the Conflicts-of-Interest Movement. New York, April 2008.

[3] Kassirer J. On the Take. How Medicine's Complicity with Big Business Can Endanger Your Health. Oxford: Oxford University Press, 2004.

[4] Greenberg DS. Science for Sale: The Perils, Rewards, and Delusions of Campus Capitalism. Chicago: University of Chicago Press, 2007.

[5] American Medical Association, Report 1 of the council on ethical and judicial affairs (CEJA Report 1A-08). Industry support of professional education in medicine 2008. Available at: http://www.amaassn.org/meetings/public/annual04/cejacme.doc.

[6] Thompson, DF. Understanding conflict of interest in medicine. N Engl J Med 1993; 329: 573-76.

[7] Emanuel E. and Thompson DF. Conflicts of Interest in Oxford Textbook of Research Ethics, ed. E. Emanuel. Oxford University Press, 2008).

[8] Brennan T, Rothman D, Blank L, et al. Health industry practices that create conflict of interest. A policy proposal for academic medical centers. JAMA. 2006;295:429-433.

[9] Association of American Medical Colleges (AAMC). Report of the AAMC Task Force on In- dustry Funding of Medical Education to the AAMC Executive Council. Washington, DC: Association of American Medical Colleges; 2008. Available at: http://www.aamc.org/research/coi/industryfunding.pdf [10] Campbell E. Doctors and drug companiesscrutinizing influential relationships. $N$ Engl J Med 2007; 357:1796-7.

[11] Bekelman JE, Li Y, Gross CP. Scope and impact of financial conflicts of interest in biomedical research: a systematic review. JAMA. 2003;289:454-65.

[12] Kelch RP. Maintaining the public trust in clinical research. N Engl J Med 2002; 346: 285-7.

[13] Rothman K. Conflict of interest: the new mccarthyism in science. JAMA 1993;269:2783

[14] Stossel T. Regulation of financial conflicts of interest in medical practice and medical research: a damaging solution in search of a problem. Persp Biol Med 2007;50:54-71.

[15] Stossel T. Has the hunt for conflicts of interest gone too far? Yes; and Lee K. Has the hunt for conflicts of interest gone too far? No. BMJ 2008;336:476-77.

[16] Boyd EA, Lipton S. and Bero LA. Implementation of financial disclosure policies to manage conflicts of interest, Health Affairs 2004; 23(2): 206-214.

[17] Ehringhaus S H, Weissman JS, Sears JL., Goold SD, Feibelmann S, Campbell EG. Responses of medical schools to institutional conflicts of interest. JAMA 2008; 299: 665-671.

[18] Steiner D, Emanuel E. Institutional Conflict of Interest, $N$ Engl J Med 1995; 332 (4): 262-67). 